\title{
A Design of an Autonomous Agricultural Robot to Navigate between Rows
}

\author{
I.H. Celen, E. Onler \\ Faculty of Agriculture, Dept. of Biosystem Eng. Namik \\ Kemal University \\ Tekirdag, Turkey
}

\begin{abstract}
An ultrasonic distance measuring based row guidance method is presented to guide a robot platform which is designed independently to drive through the row crops in a field. The offset of the robot platform are detect-ed real-time for guiding the robot inside the crop row and also turn at the end of the rows to adjacent row au-tomatically. Preliminary experiments of row guidance were implemented in rose field. Experimental results show that algorithms of row guidance and headland turn are according to the parameters measured and ana-lysed such as the offset for row guidance and the difference between the motion trajectory of the robot and the expected trajectory. The accuracy of row guidance is $\pm 70 \mathrm{~mm}$ at the speed of $1 \mathrm{~m} / \mathrm{s}$. Tractacus got the 3rd place at free style category of Field ROBOT Event 2012 with smart spraying application which is starting to spray only if it sees the crop canopy.
\end{abstract}

Keywords-ultrasonic sensor; navigation; row guidance; agricultural robot

\section{INTRODUCTION}

Agriculture sector is labor intense, predominantly depending on man power. However, in countries where labor is scarce, the cost of employing agricultural workers is high and most importantly, agricultural yield is high, there is a tendency toward a highly automated agriculture. Automation is required not only during the whole process of growing plants but also during the storage and transportation of the agricultural products [1]. Every technological automation application contains elements of mechatronics. In agriculture, the detection of crop, plant and animals, harvesting and maintenance of the field are among the mechatronics activities (Comba et al. 2011).

The use of robots in agriculture sector has a wide range of purposes. The value of using robots in agricultural activities is providing significant value to farmers. In agriculture, mechatronics is used in seeding, pest control robots autonomous and remote controlled, crop damage robots, feeding and irrigating robots, milking machines, crop categorization and processing robots without any categorization. This robot with its sensors can gather data from its environment, analyse the data, make decision based on the data, then send command to other parts to take action and finally stop the robot.

In all agricultural robots sensors play a key role. They range in complexity from simple to sophisticated. Thanks to agricultural crops, robot sensor systems are widely used. For

\author{
E. Kilic \\ Vocational School of Technical Sciences, Agricultural \\ Machinery Program, Namik Kemal University \\ Tekirdag, Turkey
}

instance, plant cutters have vibration analysis liquid flow, and sensitive agriculture has GPS.

In factories, the interaction between robots and human are more systematic and protected. However, in agriculture this is not the case and such systems are not available. To make the matter worse, people must work together in agricultural work. This puts human life at more risk, since the interaction is relatively more. As a result, security systems must be developed accordingly.

Many studies about autonomous robot for agricultural applications can be found in scientific literature (Comba et al. 2010; Bakker et al. 2010; Slaghter et al. 2008) In most cases robotic platforms have be conceived to operated in open field, Where autonomous guidance is rather complex owing to the lack of fixed references as well as the variability of the operative environment. For this reasons only in very rare cases prototypes have achieved a commercial stage. On the contrary, pot-plant nurseries are more suitable to the introduction of autonomous robotic platform than open field (Belforte et al 2006; Comba et al 2011)[2].

In this study, software and a robot which runs on this software was designed so that it could navigate be-tween row, turn at the end of a row, and handle tasks assigned to it autonomously. This agricultural robot was named TRACTACUS.

\section{MATERIAL AND METHODS}

The robot developed has an electric motor system, two prime wheels and two omni wheels, a control unit mounted on top of it, and it can move in-between rows without touching them, turn at the end of the row and enter the next one. Figure 1 shows all the components of Tractacus.

Chassis is made of lightweight material, fiberglass $5 \mathrm{~mm}$ in thickness. Likened to a box, the chassis system has a round front where sensors can sit at different angles. All the components are secured to each other with bolts. Assembly holes are drilled so that components could be put together. Moreover, holes were drilled on top of the chassis for cables. The electronic unit is mounted inside. A covering is used to protect the electronic units from external conditions [3-5].

Ultrasonic sensors, MB1040 LV-MaxSonar®-EZ4, produced by maxbotix are used in the study. LSM303 slope compensated compass module is also used (Figure 3) [6]. 


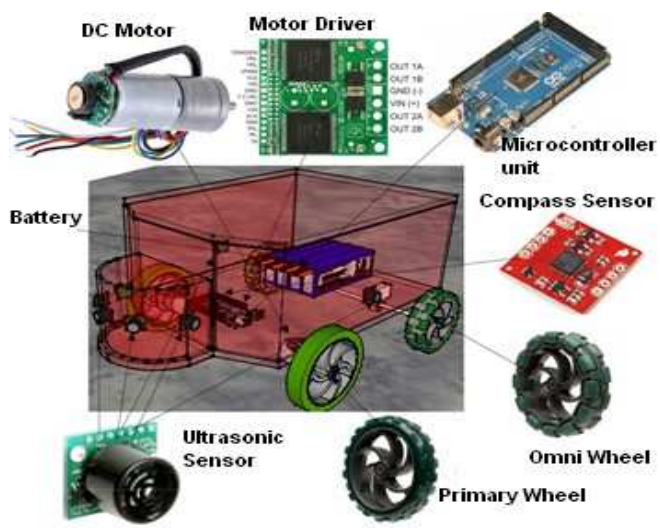

FIGURE I. COMPONENTS OF THE AGRICULTURAL ROBOT.

As a main control unit, Arduino MEGA I/O is used to analyze data coming from the sensors and adjust motors based on such data. A programming language, Arduino developed by Arduino is used to run the robot.

Dual VNH2SP30 Motor Driver Carrier MD03A model DC motor card is used to run the motors so that control card can operate the robot (Figure 3) [7]. The motor card has two channel, and it can operate and control two motors at the same time. Differential driving technique is operated accordingly.

In order for Tractacus to move, two DC motors with a 75:1 drive wheel are used. The robot has a front wheel drive. Each front wheel is controlled separately and this makes it possible to drive the robot. Technical features of DC motors are:

- $6 \mathrm{~V}$ operating voltage

- $\quad 130$ RPM maximum turn speed

- 130 oz-in torque

- Maximum load capacity 6 A voltage

- $450 \mathrm{~mA}$ current

Tractacus has a front-drive wheel. The front wheel is produced by VEX company, each of which has a 5 inch diameter. Because of cogwheel surface, and the quality of the material, it can move on different grounds. DC engines are directly embedded in wheels.

Differential driving technique is used and it requires that rear wheels can show increased resistance and therefore could easily turn. To achieve this purpose, Omni wheels are used with its multipurpose feature. They can turn just like regular wheels and as a result of custom-made design, Tractacus can also move sideways. When Tractacus is driven autonomously, it has two different algorithms: one to go to straight and head turn.

The point that the robot rotates around is known as the ICC - Instantaneous Center of Curvature (Figure 2). By varying the velocities of the two wheels, we can vary the trajectories that the robot takes. Because the rate of rotation $\omega$ about the ICC must be the same for both wheels, we can write the following equations: about the ICC must be the same for both wheels, we can write the following equations:

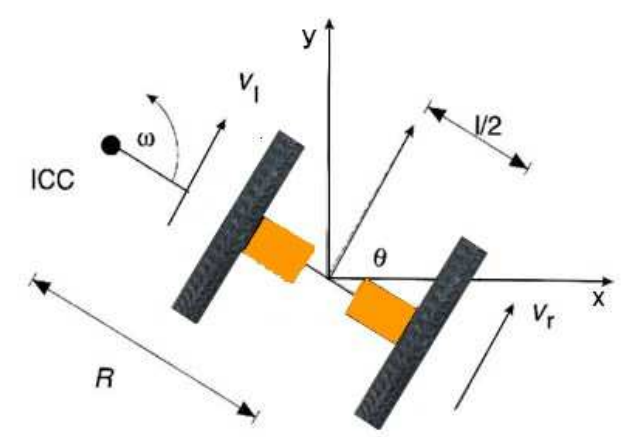

FIGURE II. DIFFERENTIAL DRIVE.

$$
\begin{aligned}
& \mathrm{Vr}=\omega^{*}(\mathrm{R}+\mathrm{l} / 2) \\
& \mathrm{Vl}=\omega^{*}(\mathrm{R}-1 / 2)
\end{aligned}
$$

Where 1 is the distance between the centers of the two wheels, $\mathrm{Vr} ; \mathrm{Vl}$ are the right and left wheel velocities along the ground, and $\mathrm{R}$ is the signed distance from the ICC to the midpoint between the wheels (Dudek et al. 2010). At any instance in time we can solve $\mathrm{R}$ and $\omega$ :

$$
\begin{gathered}
\omega=(\mathrm{Vr}-\mathrm{Vl}) / \mathrm{l} \\
\mathrm{R}=0.5 *(\mathrm{Vr}+\mathrm{Vl}) /(\mathrm{Vr}-\mathrm{Vl})
\end{gathered}
$$

1. If $\mathrm{Vl}=\mathrm{Vr}$, then we have forward linear motion in a straight line

2. If $\mathrm{Vl}=-\mathrm{Vr}$, then we have a rotation about the midpoint of the wheel axis

3. If $\mathrm{Vl}=0$, then we have rotation about the left wheel

4. If $\mathrm{Vr}=0$, then we have a rotation about the right wheel

\section{A. Straight Move}

In a straight move, Tractacus is expected to sensor sloping plants, and move forward without hitting the plants. It uses sensors number 2 and 6 to determine lines. Two threshold limits - lower and upper- are set so that Tractacus could sensor lines.

Tractacus's location is determined on the basis of the readings of the values by the sensors number 2 and 6 . Under ideal conditions, both sensors are expected to measure the same distance from the plants on both sides of the line, which in turn makes it sure that Tractacus goes right through the line.

Depending on the value read by the sensors number 2 and 6 help Tractacus determine which direction to turn: either right or left. If the value measured by the sensor number 2 is greater, then the robot makes a right turn; if the value measured by the sensor number 6 is greater, then the robot makes a left turn.

Once the direction toward which Tractacus is determined, then turning intensity is identified. If the meas-urement difference between two sensors is lower than the bottom limit, then Tractacus will not turn; if it is be-tween the upper and bottom limit, then it will make a slight turn, and if it is higher then the upper limit, then Tractacus will turn substantially. 


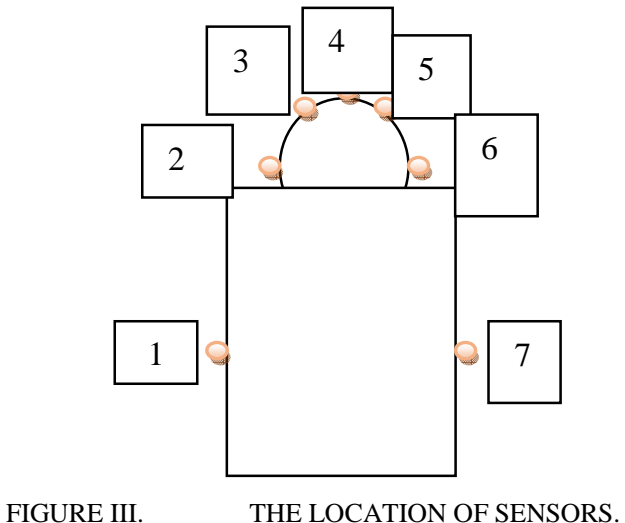

\section{B. Row-end Turn}

A different algorithm is used to determine the end of row and make the decision turn to the next line. In order for Tractacus to realize that it has reached the end of the line, sensors number 1, 2, 6 and 7 were used. When all these sensors record a value higher than the set threshold value and it determined that it has reached the end of the line, it starts to make a turn. To turn, Tractacus lock the the wheel toward the direction it needs to turn, and then it completes the turn. It takes four steps to complete this turn. It first makes a 90 degree turn, moves forward until 1 and 2 or 6 and 7 number of sensors (related to turning side) detect the row, and then it makes another 90 degree turn and keep moving till it sensors number 2 and 6 detect line distance.

Tractacus has a compass sensor to complete the 90 degree turn. The distance between the lines is measured by an encoder mounted on the engines.

Agricultural purposes;

Main purpose of this robot is navigating between crop rows automatically. The robot has to navigate through long curved rows of crops (Figure 4). On the headland, the robot has to turn and return in the adja-cent row.

In real conditions, vegetation is not fully balanced and obstacles may be presented in the fields. Also the shape of the land where the opposite sides are not parallel is considered as a standard. The robot has to take into account these variables by planning route.

Further obstacles (such as electricity pylon) can be moved in the rows and block the path of the robot. The robot has to move backwards and continue with the next row at these situations.

This robot has a special mechanism which could receive signals to use during such agricultural operations as spraying pesticides, irrigation, fertilizing, and so on. It can sensor objects within a certain distance and give on/off signal. For instance, when it detects plants, it could start pulverization system.

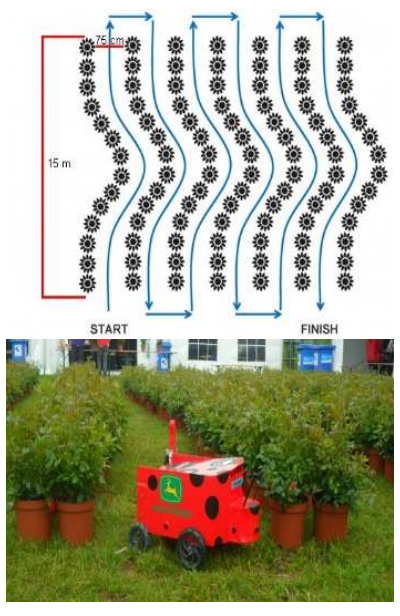

FIGURE IV.

SAMPLE OF CURVED CROP ROWS

\section{RESULTS}

The offset of the robot relative to the crop row could be obtained by ultrasonic sensors. In order to detect the crop row an Arduino mega microcontroller unit and LV max sonar EZ4 ultrasonic sensors are equipped in the robot.

Experiments was implemented at a rose field to test the algorithm of row guidance and the control perfor-mance. The plants had $75 \mathrm{~cm}$ inter-row distance and there is no intra-row distance at rose pots, test speed of the robot was $1 \mathrm{~m} / \mathrm{s}$ and the length of the each row was $15 \mathrm{~m}$. it is noted that the plants in the field were se-lected artificially with the similar size and height.

The white diluted paint was used to drop on to the soil while robot is moving. That paint is help to visualize path of robot movement. The offset derived from the measurement from paint and real center of the rows.

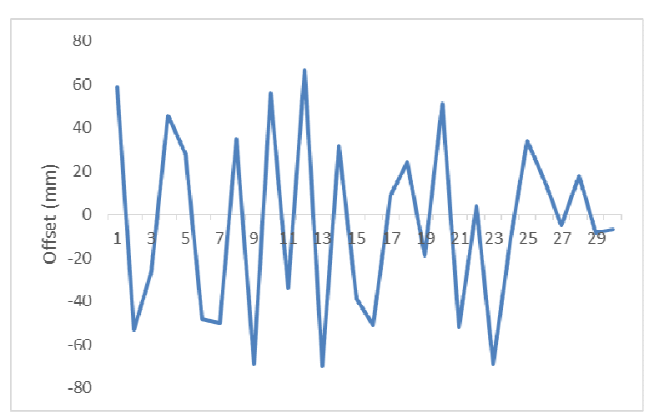

FIGURE V. OFFSET RESULTS OF FIELD TEST.

From the experimental data of Figure 5., it is shown that the accuracy of row guidance was up to $\pm 70 \mathrm{~mm}$ at $1 \mathrm{~m} / \mathrm{s}$ forward speed. Compared with the indoor experiment, the data was greater. The main reasons include some factors, such as uneven field, wheels sideslip due to soft and moist soil, also measurement errors etc. However, it can be indicated that the robot had good performance in navigating between crop rows.

\section{CONCLUSION}

Precise navigation in centimetre-precision under out-door conditions is still challenging. DGPS-navigation is still too 
expensive in relation to the small working width of field robots. Field robots are small (and presumably will stay small) because of safety reasons. Accident prevention of autonomous vehicles will remain a challenge. Here the multi-sensory system and brain of humans is unrivalled. However, certain tasks can be better done by robots than by humans, e.g. optical and sonic sensing tasks in infra-and ultra-spectral ranges.

Most promising areas are operations with following requirements and characteristics: small vehicles sufficient or even preferred (sub-canopy, low soil compaction), 24hoperation, repeated standards actions, harmful or tiring for humans, hyper-spectral sensing. Therefore, typical operations will be data collection, weeding, spray-ing, fruit harvesting.

In this study, an agricultural robot, which could navigate between rows and at the end of the row turn to the next row autonomously was developed. In addition, a special software was mounted on this robot so that it could be used for other purposes as well.

Tractacus got the 3rd place at free style category of Field ROBOT Event 2012 with smart spraying application which is starting to spray only if it sees the crop canopy.

\section{REFERENCES}

[1] Comba, L., Barge, P., Gay, P., Ricauda Aimonino, D., Tortia , C. (2011). Autonomous robot design for pot-plant nurseries. Convegno di Medio Termine dell' Associazione Italiana di Ingegneria Agraria, Belgirate, 2224 September.

[2] Bakker, T., van Asselt, K., Bontsema, J., Muller, J., van Straten, G. (2010). Systematic design of an au-tonomous platform for robotic weeding. Journal of Terramechanics, 47, pp. 63-73.

[3] Comba, L., Gay, P., Piccarolo, P., Ricauda Aimonino, D. (2010). Robotics and automation for crop man-agement: trends and perspective, International Conference on "Work Safety and Risk Prevention in Agrofood and Forest Systems", Ragusa, Italy.

[4] Dudek, G., Jenkin, M. (2010). Computational Principles of Mobile Robotics. Cambridge University Press, pp. 49, New York.

[5] Slaughter, D., Giles, D., Downey, D. (2008). Autonomous robotic weed control systems: A review. Com-puters and electronics in agriculture, 61 (1), pp. 63-78.

[6] Belforte, G., Deboli, R., Gay, P., Piccarolo, P., Ricauda Aimonino, D. (2006). Robot Design and Testing for Greenhouse Applications, BioSystems Engineering, 95(3), pp. 309-321.

[7] Sammons, P.J., Furukawa, T., Bulgin, A. (2005. Autonomous pesticide spraying robot for use in a green-house. Proceedings of the Australasian Conference on Robotics \& Automation, Australia. 